\title{
Institutional spaces and sociable eating: Young people, food, and expressions of care
}

\section{Abstract}

Young people's social relationships are fostered, enacted, and complicated by the discursive and constitutive spatial contexts in which they occur. The focus of our study was the ways the spaces of the school canteen - and the adjacent, external food environment - organised and complicated sociable eating practices for students.

Drawing on qualitative data collected from young people aged 13-15 years and staff at secondary schools, we analyse reports of the challenges posed by the school canteen space to sociable eating practices, and the importance of social relationships. The analysis highlights that young people found school canteens to be fundamentally 'anti-social' and schools do not adequately recognise or value the importance of building social skills during meal breaks. The data show that, for young people, food is often a secondary concern to sociality and the expression of kinship and care through eating together at school. Young people therefore sought spaces outside school to socialise and eat together. When socio-economic deprivation was an issue within friendship groups, the importance of caring for others emerged through ensuring peers had adequate food to eat. This analysis highlights the critical relationship between food, sociability and expressions of care in the school food environment.

\section{Introduction}

Young people's eating practices and sociality are invariably shaped by the school context, with its specific spatialities that construct knowledges, identities, and social awareness. The physical environment of the school itself - most particularly, in this instance, the school canteen and adjacent, external food environment - have been noted as sites of discomfort, overcrowding, and overregulation (Duncan 2013; Wills, Danesi and Kapetanaki 2016). Whether within or beyond the school context, young people's social relationships are 
fostered, enacted, and complicated by the discursive and constitutive spatial contexts in which they occur (Bunnell et al. 2012). As such, the focus of our study was the ways in which the spaces of the school canteen - and the adjacent, external food environment organised and complicated sociable eating practices for students attending secondary schools in England. We sought to consider the ways in which "friendship is grounded in sites and everyday spatial practices while also being attentive to the ways in which intimate relationships are embedded in wider social and political formations" (Bunnell et al. 2012) (p492). Drawing on qualitative data collected from young people aged 13-15 years and staff at secondary schools, we present findings relating to the challenges posed by the school canteen space to sociable eating practices. We then consider student accounts of the importance of their social relationships, and the ways in which they are anchored around food. In presenting these findings, we move from macro spatial analysis of the school canteen, and the manner in which it constitutes sociable eating, to a close discussion of the importance of students' social relationships, by examining the ways in which the provision and sharing of food materialises intimate expressions of care. This analysis and theoretical direction helps to mobilise social theories of practice, whereby the tacit and embedded 'act' of eating is set within the realms of values, meanings, histories, technologies, policies and resources that are inherent in the practice of acquiring and eating food during the school day (Warde 2016).

\section{Institutional Spatiality and Sociable Eating: Competing interests?}

The multi-discursive space of the school canteen may be conceptualised as a 'foodscape', which refers to a specific environment that simultaneously constructs, contests, and enforces a range of contextually specific food knowledges and practices (Johansson et al. 2009; Osowski, Göranzon and Fjellström 2012). The school canteen is, while not primarily built for 
this purpose, a fundamentally social space, shaping the ways in which food and eating are understood and enacted by the students during the school day. In examining the Swedish school foodscape, Osowski, Göranzon et al. (2012) found that students understood sociable eating in the school canteen as critical to their enjoyment and as a condition of the social belonging within friendship groups.

Crucially, the experience of those within this foodscape is not uniform. Catering staff and senior management teams are variously charged with managing lunch queues, preparing food, ensuring seating turnover, behaviour management, cleaning up and generally managing often limited space and resources. As such, a tension between staff responsibilities and student desires undergirds the school canteen foodscape, demonstrating competing interests between, as Daniel and Gustafsson write, “institutional constraints and children's agency" (p270) (see also Horta, Truninger et al. 2013).

Truninger and Teixeira (2015) examine the concept of 'care' as being 'professionalized' in school food provision, where policies instituted in many schools have focused on aspects such as portion size, energy, nutrition density and cooking methods that privilege a rational understanding of food and health by students, thus "marginalizing their bodies, and the visceral effects of food intake" (p195). As such, these institutional systems of care privilege idealised dietary intake and consumption patterns over embodied eating pleasure. Despite increased media attention paid to 'school dinners' over the last 15 years in countries such as the UK, Australia and the USA, partly through the so-called 'Jamie Oliver effect' ${ }^{\text {', the focus }}$ has largely remained on the food served rather than the symbolic meanings associated with young people eating together in school (irrespective of the food served there). This resonates with an analysis of the Australian school food context, which argues it is defined by a nexus

\footnotetext{
${ }^{1}$ See, for example https://www.thecaterer.com/news/foodservice/school-dinners-and-the-jamie-oliver-effect
} 
between 'school food pedagogies' and governmentality (Leahy 2016). While Australian schools do not provide meals for students, school food policies, school initiatives, and related curriculum directives aim to regulate food consumption and choice but fail to recognise the range of meanings food occupies in the lives of students and their families. The provision of food in schools in England has always been driven by issues regarding nutritional governance, since school food policies were first introduced in England in the 1940s. Political and subsequent policy changes to school food provision since that time have affected who is able to deliver the school food service (local authority versus contract caterers), the cost to families, eligibility criteria for receiving 'free school meals' and a significant change, in the 1980 s, from a whole meal being served to a 'cafeteria style' system whereby young people can purchase as many or as few items as they wish (Rose 2019). The publication of the School Food Plan in 2013 (Dimbleby and Vincent 2013) represented a move towards a focus on 'food' rather than nutrients and the Plan included discussion of the importance of an enjoyable eating experience for young people in schools; this aspect has not, however, resulted in any wholesale changes to practice within schools. In discussing the regulatory effect of the ethic of care, Truninger and Teixeira draw on Wright and Harwood's work on "biopedagogies" (2009). Following Foucault's conceptualisation of "biopower", Wright and Harwood use "biopedagogies" to describe the operation of power in regulating bodies through the legitimisation of certain knowledges "that enable the governing of bodies in the name of health and life" (2009: 8). However, just as Foucault asserts resistance is possible under biopower, so too can sociable intersubjective encounters around food function as a means of resisting regulatory strategies in the school context (Wright and Harwood 2009; Truninger and Teixeira 2015). As Truninger and Teixeira claim, student's lived experiences of food, their negotiation of their eating practices, and their agency in doing so create moments of rupture in the midst of the regulatory context of the school canteen (2015). 
Apart from the institutional context, in understanding the way care operates amongst young people, Neely, Walton et al (2014) present a thematic analysis of research examining the connections between young people's food practices and social relationships. Of the key themes identified, caring, belonging, reciprocity, and sharing emerged as fundamental to understanding the ways in which eating practices shape and anchor young people's social groups and friendships. In this social context food exchanges facilitate the expression of care between young people: "Ensuring friends have enough money available to participate in buying food, asking whether a friend has a sufficient amount to eat, or has eaten enough for lunch, were practices in friendships where care for others may be mediated by communicating through food practices" (Neely, Walton and Stephens 2014). A US study conducted by Kaplan (2000) also investigated food as a metaphor for care in young people's relationships within the context of US middle schools, demonstrating the ways food develops and strengthens social bonds and sustaining emotional connections, finding that, “...kids used food as an opportunity to develop skills and as a way to develop competence in caring" (p478).

\section{Commensality and Sociable Eating}

Andersen, Holm et al (2015) examine the ways in which different meal formats in Danish schools affect sociable eating. The researchers ask whether a packed lunch eliminates the possibility for a commensal eating experience, traditionally understood as the sharing of the same food (Mintz 1985; Fischler 2011). However, while more individualised eating practices have become a feature of modern societies, the potential for sociable eating is not lost: as Andersen, Holm et al. (2015) assert, the definition of commensal eating can clearly be expanded from an understanding of the elision of the individual in service to the collective experience (see Simmel 1997), to include individual eating practices within a fundamentally 
social encounter (Andersen, Holm and Baarts 2015). The authors write of new ways of understanding commensality:

...it involves sociality of the kind involved in the wide exchange patterns that occurs when one person exchanges, shares, or 'buys' foods in exchange for something else, such as friendship or attention (Andersen, Holm et al. 2015, p412).

As such, reconfiguring dominant understandings of commensality permit a means of managing the tension between individuality and sociality - in this instance, between individual packed lunches sent from home and meals served at school. Most importantly, as the authors point out, key to commensality is sharing, hospitality and reciprocity (Andersen, Holm and Baarts 2015; Wills 2018).

Sobal (Sobal 2000) writes that, "Sharing food in commensal eating builds and reinforces mutual bonds of reciprocity that express shared sociability." (p123-124). Further, Danesi (2012) stresses that sociability is grounded in the concept of hospitality, which, she argues, is "used to establish a relationship or to reinforce an already established relationship by converting strangers into acquaintances, enemies into friends, friends into better friends, outsiders into insiders, non-kin into kin" (p156); (Selwyn 2000; see also Lugosi 2008; Danesi 2012).

Where sociality refers more broadly to a membership of a social group, we have chosen to make use of the term sociability in much of our discussion as we understand it to refer more specifically to a particularly fond closeness among a social group, and as a term that perhaps describes more closely the active nature of 'doing' social relations, rather than simply the nature of being social in itself. Given our interest in exploring food sharing as an active expression of care, sociability and 'sociable eating' best define moments where young people express reciprocity and affection for one another, and where food acts as anchor to this 
process. In other words, sociability as a practice amongst young people is not simply in the 'doing' of eating, but in the active deepening of social bonds, and in the formation of one's own identity. In this way, the question for us is not the meaning of food within young people's lives, but the ways in which food enables and demonstrates intimacies and exchanges of care within social relationships centred around the school setting. To this end, here we argue that if we more meaningfully centralise the importance of supporting young people to foster social relationships and to give and receive care through sociable eating, we give schools the opportunity to shape the institutional context differently; students may then have the opportunity to better understand themselves and others.

\section{Research design}

To explore young people's sociable eating practices this study used a qualitative design encompassing focus groups with young people and interviews with relevant adults within schools. After receiving institutional ethics approval for the study, we snowballed from initial, professional links with school head teachers to identify secondary schools willing to be involved. We wanted to include schools that differed in terms of their socio-economic status and nearby food environment to explore whether and how these factors influenced sociable eating and peer relationships and our search focused on three local authority areas in East/South East England. Socio-economic status was determined using the Index of Multiple Deprivation file included in the English Indices of Deprivation 2015. Four schools participated, two within East London and two within the county of Essex. Young people in school years 8 and 9 were the focus (aged 13-15 years). This mirrors other studies we have conducted (Wills et al. 2005; Wills et al. 2019) whereby young people in year groups 8 and 9 are selected because they have 'settled in' to secondary school after their first year but then face combining reflexive practice with negotiating collective peer group interests (Fletcher et al. 2013). We sent leaflets to the parents of year 8 and 9 pupils, via the school, before 
distributing information about the study to young people. The research team made presentations to year groups about the forthcoming project and they were invited to participate. Written consent was obtained from all those who participated in focus groups. Two focus groups were conducted at each of the schools, one involving year 8 pupils and one involving year 9. Between 8-15 pupils participated in each group and each discussion lasted for a whole class period of roughly one hour, offering the opportunity for students to offer their own perspectives as well as discuss them within a group dynamic (Barbour 2008). Focus groups were audio recorded with the consent of those present and the groups were facilitated and moderated by two members of the research team. Each focus group began with a presentation about the study and our interest in pupil perceptions of the food environment within and outside their school. We presented photographs we took of the canteen and seating areas in each school, as well as the kinds of foods available for them to purchase. We also featured images of fast food and popular supermarket items such as chocolate and sweets to prompt discussion about external food retailers they might frequent on their way to and from school. Questions drew from an earlier study by the authors (Wills, Danesi and Kapetanaki 2016) and focused on what young people ate, where, with whom, and why. We prompted students to discuss the widest possible scope of their perceptions towards eating in the school context, and in the local area, asking questions about free school meals, 'going hungry', financial considerations around food purchasing habits, peer influence on their eating practices and family attitudes to their food choices.

In addition to focus groups with young people we conducted individual interviews with each head or deputy head teacher $(n=4)$ and the kitchen supervisor or a member of the catering team $(n=4)$. Questions to these individuals focused on the policy and practice of providing food in school (process for paying for food at the point of sale; service outlets available; menu development; canteen facilities), perceptions of the local food environment (whether 
students frequented local takeaway shops, for example; views about accessibility of local food outlets), and observations of student eating practices (whether young people were perceived as buying 'meals' or 'snacks' or as prioritising leaving the canteen to be with friends); these interviews helped provide context for young people's responses.

Focus group and interview data were transcribed, and, together with fieldnotes and photographs taken by the research team of the school canteen/context and adjacent, external food environment, these data formed a dataset that was imported into NVIVO for management and analysis.

In the first phase of analysis, all written data were coded in NVIVO to identify broad rubrics emerging from the dataset. The second phase of the analysis was undertaken using line-byline analysis to identify specific themes emerging within and across the broad categories identified in the first phase (Braun and Clarke 2006). This involved a closer examination of specific themes emerging from each respective school site. At each stage of the analysis, themes emerging from the data were discussed by the research team.

An overview of each participating school is given below, before the key thematic findings relating to sociable eating are presented.

\section{Findings}

School 1 is located in East London, with more than 1500 food outlets in the local area, including large supermarkets, fast food chains, and independent retailers ${ }^{2}$. Approximately half the student body are currently eligible for free school meals. This is significantly higher

\footnotetext{
2 These data were drawn from the Food Environment Assessment Tool developed by the Centre for Diet and Activity Research (CEDAR) at the University of Cambridge (2017). The FEAT tool was used to search for food retailers within the postcode area of each respective school, including takeaways, supermarkets, cafes, convenience stores, restaurants and specialty food outlets.
} 
than the national average ${ }^{3}$, as is the average pupil premium funding ${ }^{4}$. The proportion of students from minority ethnic backgrounds is much higher than that found nationally ${ }^{5}$, with approximately three-quarters of students having a first language other than English. The school is situated in Lower Super Output Area (LSOA) with the highest possible Index of Multiple Deprivation ${ }^{6}$.

School 1 is modern, featuring a central, open plan canteen with student seating. Food can only be eaten in the canteen and not in the playground, and there is a secondary eating area where snacks and cold food can also be purchased. A high proportion of students purchase food at school, while students can also bring packed lunches from home. The school runs a breakfast club daily and serves food at morning break time and during the 40-minute lunch period. However, students registered for free school meals are only able to purchase food from their allowance at morning break or during lunchtime, but not both. A token system operates during breaks to manage the volume of students purchasing food, and teachers manage this process by allocating small numbers of students in 'batches' to different hot and cold food queues. Apart from the senior sixth formers, students are not allowed to leave the school grounds during the day to purchase food or for any other reason.

School 2 is also located in East London, with approximately one fifth of the student population currently eligible for free school meals, and close to half have been eligible for the scheme during the past six years. More than $45 \%$ of students have a first language other than

\footnotetext{
${ }^{3}$ In 2017, the national average of secondary school students eligible for free school meals in the United Kingdom was 12.9\%, as reported in the statistical report Schools, pupils and their characteristics: January 2017

${ }^{4}$ Pupil Premium Funding is provided to schools each year as a grant from the Government's Department for Education based on the number of students eligible for free school meals, to provide additional funding (£935 per child per annum, currently) to help schools address disadvantage across their student body.

${ }^{5}$ In 2017, the national average of minority ethnic students in state-funded secondary schools in the United Kingdom was $29.1 \%$, as reported in the statistical report from the Department of Education, Schools, pupils and their characteristics: January 2017 UK Department of Education (2017). National Statistics - Schools, pupils and their characteristics: January 2017.

${ }^{6}$ The data were obtained from the Index of Multiple Deprivation file included in the English Indices of

Deprivation 2015.
} 
English, which is again above the national average. The school's LSOA has a high IMD, meaning the school is categorised as being within a socioeconomically deprived area, but it has fewer food outlets nearby compared with School 1, with just over 320 food retailers in the surrounding area. Students must remain on campus during break times to eat, and only those with express permission from their parents and a lunch time pass may leave the school to eat lunch at home. The main canteen serves the student body, though students can elect to bring their packed lunch from home. The canteen has limited seating, and lunch times are staggered across year groups, to manage overcrowding.

School 3 is a modern, well-equipped facility in a rural part of Essex, a county to the East of London. Staff self-describe the school as serving a predominantly middle-class, monocultural demographic, with only $10 \%$ of the student population from a Black and Minority Ethnic (BAME) background. Less than 2\% of students are eligible for free school meals. However, while acknowledging the affluence of the school community overall, it was noted by staff that they do also see families in crisis who are victims of rural deprivation and poverty, and the school does its best to assist them when necessary. The school is in an LSOA with the lowest possible level of deprivation (as measured by IMD), and there are 60 food outlets in the nearby village.

All students except for sixth formers (the most senior secondary school year groups) must remain on campus to eat. Students are permitted to bring packed lunches, but only about $7 \%$ of students do this each day, meaning most students purchase food in school. The school has eating segregation policies in place: only students who purchase food in the canteen itself are permitted to eat in its seating area, while those with packed lunches must sit in other allocated eating areas. Additionally, due to space limitations, the school has staggered sittings for lunch to admit all students to the canteen to eat. While the school has several food outlets and seating areas for students, some are only for senior students. 
School 4 is a modern Christian faith-based school, situated in Essex. Staff report a mixed demographic in the school community, ranging from affluence to poverty, though the school's level of pupil premium funding is quite low. BAME students make up roughly a third of the student population, and approximately $12 \%$ of students are eligible for free school meals. The school's LSOA has a mid-range classification for deprivation as measured by the IMD, with approximately 20 food retailers nearby, making it the school with the fewest local outlets.

Junior students must remain onsite during breaktimes, and the school operates a staggered seating during the lunch hour due to limited seating adjacent to the canteen. The school also runs a breakfast club daily. Students are permitted to bring a packed lunch, though only 10$15 \%$ of students were estimated by staff to do this each day.

\section{School Eating Spaces as Barriers to Sociability}

At Schools 1 and 2, dining was recognised by the staff interviewed as an important sociable and social learning experience. School 1 offers all students free breakfast at school in order to offer a social space for students to come together, without stigma or scrutiny, and enjoy breakfast together 'somewhere just nice' (Head Teacher), and in School 2, staff have elected not to institute a policy separating students who bring packed lunches from those who eat school meals because 'it teaches them that eating is actually a social experience' (Head Teacher).

However, our research underlined an issue faced by many schools: the impact of large student populations and overcrowded canteens on sociable eating. Other studies have examined noisy canteens, overcrowding, limited seating, and students feeling hurried to eat as barriers to the sociable eating experience that students seek during lunchtimes (Daniel and Gustafsson 2010; Horta 2013). While staff demonstrate a commitment to the importance of 
students developing social skills, they are also responsible for managing large number of students with often limited resources within schools, introducing competing interests for staff and students over the facilitation of sociable eating at break times. As such, it emerges that the institutional 'biopedagogical' imperatives to accommodate students appropriately and maintain a standard of nutrition take precedence over student sociable eating. This, as Daniel and Gustafsson assert, is "illustrative of a particular food culture that places emphasis on nutrients and individual healthy choices over those of sharing pleasure over a meal" $(2010$, p273).

A desire to escape the noise and chaos of the canteen as troubling to the social experience of dining was a theme raised by students at all schools in the study, who experienced the noise and overcrowding as promoting a fundamentally 'anti-social' experience quite apart from the functional, practical aspect of accommodating students to eat. Further, the issue of overcrowding emerges as an obstacle to the reliability of finding friends at lunch times to sit with them and share food.

It's also hard for like new year sevens [first year at secondary school]. Like I remember when I was in year seven it was so hard to find a space to sit, and you just don't want to be alone. Even if it's with one more, just like one individual person with you, it's really hard to just find two seats (Year 8 student, School 1).

In this instance, students may not have opportunity to sit down to eat, with or without their friendship group. Despite the absence of official eating segregation policies, School 2 students experienced their mealtimes as clearly divided, and as such, as fundamentally antisocial:

“...like say you wanted to like...you had already eaten or something and you wanted to go and sit with your friend, you're not allowed in like if you haven't got lunch. So 
like say all your friends are sitting down you wouldn't be allowed to just walk in and like sit with them" (Year 8 student).

As is the case with Schools 1 and 2, eating segregation policies caused consternation among students at Schools 3 and 4 who also feel it forces social divisions. These schools have eating segregation policies in place to manage large numbers of students and limited space, separating those who bring packed lunches from those who purchase food at school.

...I can see it must be so irritating for people who maybe want to sit with their friends...But then I can kind of understand because the canteen is extremely cramped already...more people being added to it would just make the whole situation worse (School 3, Year 9 student).

This student response evidences an awareness of the competing interests around the space of the school canteen: while affirming the impact on students who cannot sit with friends, the student also notes the pressures on the school to accommodate all students at lunch time. However, student responses overall frame the removal of the ability to sit with friends to share lunch as a basic need requiring respect, not simply as a recreational deficit:

School isn't just about learning facts and figures and different things, it's about learning different social skills as well, and if you're not allowed to sit with your friends at lunch then you're not learning social skills, you're just learning rules and discipline (Year 9 student, School 3)

As this comment demonstrates, students understand sociability as playing a key role in their education and as central to their development, capacity for empathy, and relational literacy. 
However, as noted by the student above, a dominant assumption persists that the core mission of the school is the provision of formal education, which students do not perceive as adequately recognising or valuing the importance of building social skills and networks.

In response to overcrowding and space limitations curbing and complicating the establishment or maintenance of social bonds, students spoke of the drivers for their friendship groups to go to external food outlets on their way to or from school, free of the restraints and noise of the school canteen:

\author{
Student: We just go to chill. \\ Researcher: Sometimes you go in just to be together but outside of school? \\ Student: Yeah (Year 9 student, School 1).
}

What was evident was the dual appeal of autonomy in choosing food, but also the chance to socialise around food in more comfortable environs. While students were often enthusiastic about adjacent, external food outlet options, there was a recurrent theme of the importance of finding a space and a time to simply be together with friends - to 'chill' on their own termswhere independence and autonomy defined their collective sociable experience as opposed to their eating experiences within the school environment. As such, what became clear from the focus groups we conducted with students at all schools studied is that food itself becomes a secondary concern to the importance of social companions.

\title{
The Provision of Food as The Exchange of Care
}

Recurrent cultural narratives are repeated about the 'problems' with 'today's youth', who continue to be negatively perceived as self-absorbed and narcissistic (Arnett 2007; Trzesniewski and Donnellan 2014 ), looking inward rather than forging connections to the 
world and the different life experiences of others. However, our research findings indicate a very different reality. Caring for others through food functions as a protective act, an expression of kinship, a means of alleviating stigma and distress of vulnerable students, and a way of ensuring the deepening and preservation of social bonds. The below conversation took place during a focus group of Year 9 students in School 3, which was the most affluent of all the school sites studied:

...I've got friends who sometimes miss their lunch because they don't have enough money on their account and I have to buy them something because they can't afford to buy something every single day.

I've had to do it for some people.

My mum says I can't buy other people food anymore because I was doing it so often that I was running out of money on my own account.

There is someone who I, in year seven, I had to buy them lunch quite often. And then they didn't even have money to like pay me back.

Researcher: Right, okay. And how did that make you feel?

I didn't mind as much because they were getting food.

... I sometimes used to buy things for my friends, maybe like once or twice a week, and...it came to quite expensive just me and my sister also spending more money on a 
friend who doesn't have enough money at that time to get something, it just, it does come up a bit high.

I have to buy some, like my friend lunch three times a week...like because he never has money on his account. And like I actually quite enjoy buying him meals because sometimes he doesn't get hot meals at home or anything, so it's quite nice...

I think it can be hard because you're trying to be kind to everybody and sometimes there have been occasions where three friends haven't got something at lunch and I've had to skip lunch to buy them something, but then it's hard to be kind to everybody and also be kind to yourself (Year 9 students, School 3).

It is possible that such actions of kindness are calculated at some level to curry favour with others in order to be well-regarded and valued by them as friends, and to generate social benefits. However, what is poignantly evident from the student responses in the above discussion is that sharing and purchasing of food for others is more likely driven by an ethic of care, where social bonds are marked by generosity and nurturance. Food is offered as an emblem of empathy and affection, as well as demonstrating an awareness of need, privilege, and hidden deprivation. Students with the capacity to pay for friends (even those who sometimes must go without themselves to buy food for their friends with no money) purchase more than sustenance - rather, the gift of care is what is exchanged. However, it should be noted that this school was the most affluent of all those studied. Given this, who is privileged to be in the position of the giver, and what does it mean to accept gifts from others in the context of deprivation? Some students from schools in more affluent areas may not need to consider the cost of gifting food to others, and those to whom it is gifted may not ever be in 
the position of reciprocating those gifts. As such, the enactment of sociable eating practices is also underpinned by a fundamental inequality (Fletcher, Bonell and Sorhaindo 2011).

\section{Individuality and/or Belonging? Conflicting Narratives of Peer Influence}

We asked students whether their friends influence what, and when, they choose to eat. An internal contradiction regarding this influence emerged in student responses: on the one hand, they asserted the core importance of having their individual identities recognised, to exercise the right to make autonomous, independent choices, and to be perceived by their social groups as doing so. Yet, on the other hand, there was also a simultaneous stated desire to belong, and to share the same foods with friends and ensure participation in the sociability aspect of eating. What was clear in these contradictory accounts was that any influence of one's friends on one's food choices is driven by the desire to belong. In this way, food is used to facilitate togetherness and to anchor a shared social experience, rather than because of the specific choice of food itself.

I think most of the time if you go to eat with your friends it's not like to eat same as them, just to be able to talk to them, so...

My friends don't influence what I eat, it's just sometimes none of us are hungry and so we just don't go to the canteen (Year 8 students, School 3).

Students also framed their decision to share food not as a question of influence, but as a means of expressing friendship and togetherness.

I never buy a hot meal but sometimes like one of my friends will buy it and then like three of them will share it. And like the next day another one will buy it, so they end up each buying one meal that they share it between (Year 8 student, School 3). 
Students at School 4 also offered responses that demonstrated a conflict between the need to be recognised as an autonomous individual and the need to be part of a close social group:

I feel like my friends don't really affect the way I eat... What I eat, it's my decision... Like if my friend was like all of a sudden wanted to become a vegetarian, then I would be like 'Yeah, we'll do it together' it doesn't affect like if I'm eating and then it doesn't affect whether I'm eating or not. Like if I get hungry then I'm going to eat, I'm not just going to like not eat something just because they're not... (Year 9 Student, School 4).

In noting the influence of peers on eating, other students offered different perspectives: ...If my friends are being healthy then I probably will be healthy with her. But if she's eating junk food, I'll eat junk food with her (Year 9 student, School 4).

This admission of the influence of friends on food choices gave way to the very act of eating (or not eating) during sociable encounters compromised one's sense of belonging within a group of friends, particularly where the crowding and noise of the canteen motivates students to avoid eating and escape an uncomfortable environment:

I don't know...it sort of feels like you're a bit like the odd one out because they're not really eating anything and you are. It's not like affecting my decision on whether I'm going to eat or not, it just makes you feel a certain way about it...

...I still feel sort of self-conscious because I do get hungry, I do eat at lunch, some of my friends don't so I have to sort of be awkward. (Year 9 students, School 4).

In this instance, instead of food anchoring sociability, it complicates it, and is perceived as fracturing togetherness which introduces a conflict in individual students between meeting 
their own needs for food and their need to belong. As such, where sociability emerges as a core desire for students, food itself often appears to, in some ways, 'get in the way'.

\section{Escaping the Canteen: Sociable Eating outside of school}

Set against the often anti-social environment of the school canteen, studies have affirmed the goal of going to food outlets is to be with friends in a pleasant place rather than the food/drink itself (Bugge 2010; Neely 2015; Wills, Danesi and Kapetanaki 2016). When asked about visiting food outlets before and/or after school, we found that students sought spaces to socialise around food that were more relaxed and thus conducive to socialising. More than simply offering a wider selection of food options and cheaper food, this external purchasing appears to offer a different and more comfortable social context for students to socialise on their own terms, and on their own time, thereby enacting their 'collective independence'.

Staff told us that students at School 4, particularly those in Year 9 and upwards (aged from 15 to 18 years), made regular plans to socialise in nearby chain eateries, especially on scheduled half days off school each week. A local supermarket chain was frequently named as a favourite local outlet visited by students daily on the way to and from school. When asked about whether there was a social element to converging on this shop, students agreed this was the key consideration:

If it's after school my friends are getting the bus and then we'll be like 'Oh, are you going to Sainsbury's?' and we'll all just go in ... (Year 9 student, School 4).

It was evident in School 4 student responses that while sharing food unquestionably facilitated friendships and togetherness, unlike some responses from other schools visited, the foods chosen to share - in this instance, sugary, sweet foods — served a more 'inclusive' function in bringing groups of friends together to eat sociably: 
I don't really go to [supermarket] that much to buy sweets and stuff, I might sometimes like on a Friday. I usually share stuff that my friends offer to me on the bus, like usually my friends, they come on the bus with massive trays of doughnuts and they share it with everyone (Year 8 student, School 4).

...We all like know what we're buying so like if someone is buying something on the train to like share it, if two people want a drink then they'll share a drink, share food with each other (Year 9 student, School 4).

... if one of my friends brings a bag of sweets then I'm going to eat it with her, because it's sweets and we can all share it together. But if one of my friends brings, I don't know, something else that you can share that's a bit more healthy then they'll probably just eat it. It's not really as much of an inclusive thing to bring something healthy. (Year 9 student, School 4).

In this way, these foods are shared as gifts between groups of friends, where certain foods are a 'special treat' that trace lines of closeness across groups of friends, but are enjoyed not simply as a treat, but as the anchor to a sociable eating experience. As the last quotation above notes, the meaning of exchanging food between friends is disrupted in this context if the food is understood as 'healthy' — but interestingly, again, even if the food being shared was healthy rather than a sweet treat, it would still be accepted and eaten as part of the sociable eating encounter but the perception of the encounter is different.

\section{Sharing Food as Exchange of Care}

Kaplan (2000) explores informal networks of care between students, focusing on students who wished to resist the stigma of accepting free lunches from within schools, which entailed going to a specific counter, thus making one's deprivation evident to other students. She suggests the acceptance of the gift of food from friends means something different from 
accepting free school food, whereby connections are forged between students, class differences are ameliorated, and care is enacted in a more intimate and meaningful way. This is supported by other studies which have also shown that using social groups to share food with others can enable a means of managing children's experiences of food insecurity (Connell 2005).

Where student deprivation is present, the importance of care takes on a deeper importance, where care expressed through sharing food is not simply experienced as sociable kindness, but as an act of protection by a social group that might be better imagined as fictive kin. One student notes the difficulty of negotiating the stigma of not having money to purchase food, and the critical importance of her friends' care of her during meal breaks:

...Like the rich people are quite wealthy, they've got loads and loads and then you feel quite embarrassed because you can't get all the food that they're getting or you might have to ask them to get you something...I had to ask [a friend] to get me something because I don't have money in my account, so, and it's quite embarrassing to ask because your friends, they're your friends so you shouldn't be embarrassed but I am because it's like money problems, some people do have money, if I don't have money, why do you? (Year 8 student, School 4).

The student continues, explaining the importance of her fictive kinship group in caring for her, and speaking with a mix of deep affection and gratitude to her friends, and shame in the face of the stigma of deprivation:

My friends are really caring about like my situation, I don't have it all the time, but they're 'Oh, it's fine, I'll get it for you' and then I'll be like, 'When I get money, I'll get you a drink or something', like 'You're my friend, you're not going to get me anything, it's what friends do'. So sometimes I feel quite comfortable to tell them 'Oh, 
can you get me something?' I can't take too much...So that's why I'm sort of embarrassed to say all the time...Sort of like buying someone else food because they're having trouble, like that's sometimes a big thing, and that sort of says 'Oh, they really care about me' and I'm having trouble (Year 8 student, School 4).

Here, this student discusses the awkwardness she experiences in perceiving herself as a burden on her friends, but also the safety she feels with her fictive kinship group and the way care is enacted between them as part of their responsibility to, and affection for, each other, rather than the student's need being positioned as a nuisance. In providing food for their friend, the student's vulnerability is simultaneously highlighted and erased: even as the difficulty of the student's situation informs these food exchanges, it is not the focus of the sociable eating and fictive kinship of the group. Rather, the governing principle between them can be said to be an exchange of care, where the emphasis of the food exchange is about neutralising the student's shame and socioeconomic difference and reaffirming an understanding of what constitutes their friendship.

\section{Discussion}

\section{Spatiality and Sociality in the School Canteen}

Our focus groups with students at all schools evidenced the centrality of meals breaks to learning social skills, forming bonds, and negotiating community and friendship networks, all of which can be said to be as formative to students as formal curricular content. Yet this social learning, and its core importance to identity formation, social literacy, and the development of support networks is hampered by the physical limitations of the school eating environment, where the act of sharing food with friends is a daily challenge to be negotiated rather than enjoyed.

As such, meal breaks are not simply times to eat, but are an essential part of the broader social development of students. Yet the ability to explore this social learning is perceived as 
hampered by necessary regulation of school facilities and management of space, thereby imparting a sense of sociability as of only incidental importance to the school experience. This latter notion appeared to be tacitly supported by layout of eating space in many schools, which was identified by the students we spoke to as often fundamentally 'anti-social' for everyone. Friendships are deepened at break times, and sharing food together emerges as the anchoring principle in this process. As noted by a student at School 1, the physical crowding of the canteen space can eliminate seating possibilities all together, marginalising individual students from a sociable eating experience, often just as needed, if not more so, than the food itself. As such, this fear of isolation and exclusion from the social dining experience is materialised through the restricted physical space and limited seating of the school canteen. Wills, Danesi et al (2016) similarly highlight the centrality of peer social relationships in eating practices within and beyond the school context, where external food outlets offered students a quieter, less crowded, less pressured eating experience as compared with the "antisocial" environment of the school canteen often experienced as noisy, rushed, and cramped.

The co-existence of eating and sociability emerges as vital: meal break times offer key opportunities in a school day for students to participate in a sociability that is both intimate and formative, and facilitate a means of learning about care, identity, belonging, and difference. Space management and eating segregation policies tacitly reaffirm this concept of formal education context scaffolded by rules and discipline. This is not to say these aspects are not valuable, but where students emerge as wanting a more active role in defining their identity and experiencing a degree of critical awareness and independence in a shared social context within the school environment, a corrosive conflict emerges. The development of social bonds then complicates the practical demands of managing school space and resources, and vice versa. 
The centrality of sociable eating and exchanges of care

While schools report making efforts to ensure good nutrition for students and to provide different eating options, our findings indicate strongly that the act of being together sociably is of more importance than the actual food item within the sociable encounter. However, the 'inclusive' aspect of a 'treat' was discussed by students, positioning the sociable sharing of such foods as part of a select care economy, where 'clandestine' exchanges express closeness differently to healthier foods that may be regarded more as sensible sustenance rather than tokens of care. Stead, McDermott et al (2011) also found that a conflict emerged between social meanings attached to 'healthy eating' and sociable eating practices within social groups of 13-15 year olds, where healthy foods were seen to threaten individual efforts to 'fit in' to social groups (Stead et al. 2011). In this way, young people coded certain foods in terms of social 'lubrication' and inclusiveness, and one's food choices were often driven by a desire to project a certain image to one's social group, as well as avoid social marginalisation or ridicule. While we anticipated varying concerns about the issues raised with students to emerge along gender lines, our discussions with the young people who participated in our focus groups revealed a surprising accord regarding shared frustrations with school eating spaces as a barrier to simple acts of sharing time with friends and sociable eating. There were both anxious and compassionate responses from all students about the presence of food insecurity for some of their friends, and the ways they formed networks of care around each other to address this. As such, our focus groups did not reveal remarkable gender differences in student responses, not even in discussions of things such as portion sizes or food preferences, though the female students were at times more forthcoming about discussing issues around sociality and networks of care. However, our research did not find gender as clearly and specifically marking key issues emerging from student discomfort with school eating and the desire for a more sociable eating environment. Indeed, the latter concern was strongly shared by all students we talked to, emerging as fundamental to their sense of 
improving school eating experiences, enabling a sense of individual and collective wellbeing, and strengthening social bonds.

Just as students wish to belong in social groups, necessitating individuals to make certain choices that are collectively sanctioned by the group, our research revealed an openness to care of others, and an awareness of the ways in which such exchanges of care in the form of food not only benefited the recipient but also promoted a sense of wellbeing for the giver. The care of others transcended the socio-economic gap, where one existed between pupils who were friends. As such, our findings also affirm the inextricability between self and others, and that this connection is well understood by students, particularly evident in and through the exchange of care in sociable eating. As one student at School 3 noted, about the challenges of buying food for others, "it's hard to be kind to everybody and also be kind to yourself". And yet, they went on to explain the way they had gone without food themselves to ensure their friends had food to eat. What is most evident here is the conflict between individual self-care and interpersonal care is not an either/or proposition. There is a tacit understanding from students that they are always already imbricated in a social context, even as they develop and explore their own individual identities and notwithstanding their socioeconomic background and whether or how this differs to their friends. In students' negotiation of their identity formation and presentation on social groups lies the tension between defining and expressing one's individuality (a fundamental value in most Western societies), and the desire to belong to a social group necessitating a degree of conformity (Hornsey and Jetten 2004).

\section{Conclusion}

Eating itself, as Warde (2016) asserts, is always already an activity embedded in cultural, historical, political and social discourses; eating with others is a fundamentally social exchange. Commensal eating, as Anderson, Holm, et al. (2015) affirm, are sociable 
experiences inscribed by sharing, hospitality, and reciprocity. In terms of sharing and gifting food within the school lunchtime economy, Andersen, Holm et al. (2015) note that those who bring food from home were observed to share it within their friend networks, cementing a social bond where "each gift is part of a system of reciprocity in which the giver and the taker are implicitly committed to one another" (p404). Further, in looking at the range of social and cultural contexts that organise us and that we organise, the myriad ways we share, communicate over, exclude others, or extend a welcome in and through a shared mealtime reveals that, "socialization into commensality is also socialization into sociocultural embodiments of generation, gender, and other social positionings" (Ochs and Shohet 2006).

Analysis of our data provides valuable evidence about the importance and centrality of social relationships among young people at secondary school. While other studies have focused on food and eating, with commensality emerging as important, our paper demonstrates that sociability is a core practice, with food as a conduit for deepening social bonds and intimacy. This suggests that schools need to better understand what young people miss out on when the physical space of the canteen or the regulations surrounding segregation severely hamper sociable eating. The enactment of biopedagogy, though perhaps unintentional, means young people have fewer opportunities to express care, to bridge socioeconomic gaps and to develop empathy for others. Our research finds that the nourishment food must offer in the school food environment must go beyond metrics of nutrition to afford an anchoring social practice for the development and strengthening of social bonds and relational learning. As such, a sociable eating experience at school should not be an optional extra outside of the core educational experience but a fundamental way of promoting and enhancing young people's social development and wellbeing.

\section{Disclosure statement}


Neither author is aware of any conflict of interest.

\section{References}

Andersen, S. S., Holm, L. and Baarts, C. (2015). "School meal sociality or lunch pack individualism? Using an intervention study to compare the social impacts of school meals and packed lunches from home " Social Science Information 54(3): 394-416. 54(3): 394-416

Arnett, J. J. (2007). "Suffering, selfish, slackers? Myths and reality about emerging adults." Journal of youth and adolescence 36(1): 23-29.

Barbour, R. (2008). Doing Focus Groups. London, Sage.

Braun, V. and Clarke, V. (2006). "Using thematic analysis in psychology " Qualitative Research in Psychology 3(2): 83.

Bugge, A. B. (2010). "Young people's school food styles." YOUNG 18(2): 223-243.

Bunnell, T., Yea, S., Peake, L., Skelton, T., et al. (2012). "Geographies of friendships." Progress in Human Geography 36(4): 490-507.

Connell, C. L., K., Yadrick, K. And Rehner, T. (2005). "Children's experiences of food insecurity can assist in understanding its effect on their well-being." Journal of Nutrition 135: 1683-1690.

Danesi, G. (2012). "Commensality in French and German young adults: an ethnographic study." Hospitality \& Society 1(2): 153-172.

Daniel, P. and Gustafsson, U. (2010). "School lunches: children's services or children's spaces?" Children's Geographies 8(3): 265-274.

Dimbleby, H. and Vincent, J. (2013). The School Food Plan. London Department for Education.

Duncan, N. (2013). "If you tolerate this, then your children will be next: Compulsion, compression, control, and competition in secondary schooling." International Journal on School Disaffection 10(1): 29-45.

Fischler, C. (2011). "Commensality, society and culture." Social Science Information 50(3-4): 528-548.

Fletcher, A., Bonell, C. and Sorhaindo, A. (2011). "You are what your friends eat: systematic review of social network analyses of young people's eating behaviours and bodyweight." Journal of Epidemiology and Community Health 65(6): 548-555. 
Fletcher, A., Jamal, F., Fitzgerald-Yau, N. and Bonell, C. (2013). "'We've Got Some Underground Business Selling Junk Food': Qualitative Evidence of the Unintended Effects of English School Food Policies." Sociology 48(3): 500-517.

Hornsey, M. J. and Jetten, J. (2004). "The individual within the group: Balancing the need to belong with the need to be different." Personality and Social Psychology Review 8(3): 248-264.

Horta, A., Truninger, M., Alexandre, S., Teixeira, J., Et Al. (2013). "Children's food meanings and eating contexts: schools and their surroundings " Young Consumers 14(4): 312-320.

Johansson, B., Mäkelä, J., Roos, G., Hillén, S., et al. (2009). "Nordic children's foodscapes: Images and reflections." Food, Culture \& Society 12(1): 25-51.

Kaplan, E. B. (2000). "Using Food as a Metaphor for care: Middle-School Kids Talk about Family, School, and Class Relationships." Journal of Contemporary Ethnography 29(4): 474-509.

Leahy, D., Wright, J. (2016). "Governing Food Choices: A Critical Analysis of School Food Pedagogies and Young People's Responses in Contemporary Times." Cambridge Journal of Education 46(2): 233246.

Lugosi, P. (2008). "Hospitality spaces, hospitable moments: Consumer encounters and affective experiences in commercial settings." Journal of Foodservice 19(2): 139-149.

Mintz, S. (1985). Sweetness and Power: The Place of Sugar in Modern History. New York, Viking Penguin.

Neely, E., Walton, M. and Stephens, C. (2014). "Young people's food practices and social relationships. A thematic synthesis." Appetite 82: 50-60.

Neely, E. W., M., Stephens, C. (2015). "Building school connectedness through shared lunches." Health Education 115(6): 554-569.

Ochs, E. and Shohet, M. (2006). "The cultural structuring of mealtime socialization." New directions for child and adolescent development 111: 35-49.

Osowski, C. P., Göranzon, H. and Fjellström, C. (2012). "Children's understanding of food and meals in the foodscape at school." International Journal of Consumer Studies 36(1): 54-60.

Rose, K., Lake, A.L., Ells, L.J., Brown, L. (2019). "School food provision in England: A historical journey." Nutrition Bulletin 44: 283-291.

Selwyn, T. (2000). An anthropology of hospitality. Search in Hospitality: Theoretical Perspectives and Debates. C. L. a. A. Morrison. Oxford, Butterworth-Heinemann: 18-37. 
Simmel, G. (1997). Sociology of the Meal. Simmel on Culture: Selected Writings. M. Featherstone and D. Frisby. London/Thousand Oaks/New Delhi, Sage Publications.

Sobal, J. (2000). Sociability and Meals: Facilitation, commensality and interaction. Dimensions of the Meal: The Science, Culture, Business and Art of Eating. H. E. Meiselman. Gaithersburg, MD, Aspen Publishers: 118-133.

Stead, M., Mcdermott, L., Mackintosh, A. M. and Adamson, A. (2011). "Why healthy eating is bad for young people's health: Identity, belonging and food." Social Science \& Medicine 72(7): 1131-1139.

Truninger, M. and Teixeira, J. (2015). Children's engagements with food: An embodied politics of care through school meals. Careful eating: bodies, food and care. E. J. Abbots, Lavis, A., \& Attala, M. L. (Eds.). (2015). . , Ltd.. Ashgate Publishing.

Trzesniewski, K. H. and Donnellan, M. B. (2014 ). "'Young People These Days..." Evidence for Negative Perceptions of Emerging Adults." Emerging Adulthood 2(3): 211-226.

Walker-Birckhead, W. (1985). The Best Scones in Town: Old Women in an Australian Country Town. Australian Ways: Anthropological Studies of an Industrialised Society. L. Manderson. Sydney, Allen and Unwin.

Warde, A. (2016). The Practice of Eating. Cambridge, Polity Press.

Wills, W., Danesi, G., Kapetanaki, A. B. and Hamilton, L. (2019). "Socio-Economic Factors, the Food Environment and Lunchtime Food Purchasing by Young People at Secondary School." International Journal of Environmental Research and Public Health 16(9): 1605.

Wills, W., Danesi, G, Kapetanaki, a \& Hamilton, L (2018). "The socio-economic boundaries shaping young people's lunchtime food practices on a school day." Children and Society 32(3): 195-206.

Wills, W. J., Backett-Milburn, K., Gregory, S. and Lawton, J. (2005). "The influence of the secondary school setting on the food practices of young teenagers from disadvantaged backgrounds in Scotland." Health Education Research 20(4): 458-465.

Wills, W. J., Danesi, G. and Kapetanaki, A. B. (2016). "Lunchtime food and drink purchasing: young people's practices, preferences and power within and beyond the school gate." Cambridge Journal of Education 46(2): 195-210.

Wright, J. and Harwood, V., Eds. (2009). Biopolitics and the 'Obesity Epidemic': Governing Bodies. New York, Routledge. 